\title{
Formação de professores dos anos iniciais da Educação Básica na modalidade EaD: ensino de língua materna e a influência das Tecnologias da Informação e Comunicação
}

Education of elementary school teachers in distance education: $L 1$ teaching and the influence of Information and Communication Technology

\author{
Lucilene Lisboa de Liz ${ }^{1}$ \\ Sandra Quarezemin ${ }^{2}$
}

\begin{abstract}
RESUMO
O presente artigo tem como finalidade problematizar a percepção dos professores dos anos iniciais, alunos em formação por meio da educação a distância (EaD), no que diz respeito ao ensino de língua materna, em relação: (i) à influência exercida pelo uso das Tecnologias da Informação e Comunicação (TIC) durante o seu processo de aprendizagem da língua escrita; (ii) à forma como passaram pelo processo de aprendizagem da escrita e os reflexos dessa experiência em sua prática docente; (iii) à influência do uso das TIC na escrita dos seus alunos; e (iv) à concepção de língua adotada por esses professores. Em termos metodológicos, trata-se de um estudo de natureza qualitativa em que os sujeitos de pesquisa são alunos do curso de Pedagogia da Universidade do Estado de Santa Catarina (UDESC), na modalidade a distância. Quanto ao instrumento de coleta de dados, procedeu-se à aplicação de questionários em quatro polos de EaD.
\end{abstract}

Palavras-chave: formação de professores; ensino de língua materna; Tecnologias da Informação e da Comunicação; Educação a Distância.

DOI: $10.1590 / 0104-4060.38659$

1 Universidade Federal de Santa Catarina, Curso de Pedagogia a Distância. Florianópolis, Santa Catarina, Brasil. Avenida Madre Benvenuta, 2007. CEP: 88035-001.

2 Universidade Federal de Santa Catarina, Departamento de Língua e Literatura Vernáculas. Forianópolis, Santa Catarina, Brasil. Centro de Comunicação e Expressão. Trindade. CEP: 88040910. 


\begin{abstract}
This very article has the purpose of discussing the perception of teachers of the initial school years, graduating students through distance education (DE), about teaching the Brazilian language, in relation to: (i) the influence exercised by Information and Communication Technologies (ICT) during the learning process of the written language; (ii) the way they went through the learning process of written language and the reflections of those experiences upon their given lessons; (iii) the influence of ICT use in the writing skills of their students; and (iv) the language concept adopted by these teachers. From a methodological view, it handles about a qualitative study in which the researched subjects are pedagogy students from the Universidade do Estado de Santa Catarina (UDESC), in the distance modality. To collect data, the procedure was to apply surveys in four DE centers.

Keywords: teacher education; Brazilian language learning; Information and Communication Technologies; Distance Education.
\end{abstract}

\title{
Introdução ${ }^{3}$
}

Dentro do contexto atual, de uma sociedade invadida por diferentes tecnologias, torna-se evidente a presença de traços linguísticos, característicos tanto da oralidade quanto da escrita, de gêneros discursivos que integram e circulam nesses meios tecnológicos. Diante disso, o olhar do professor para a produção escrita da criança, foco deste estudo, não pode se furtar de considerar esse aspecto.

Nesse sentido, são preocupantes alguns comentários sobre o tema, daqueles que afirmam que a escrita da internet, presente em bate-papos, redes sociais ou mesmo em e-mails, está contaminando a língua ou a pureza dela. Pelo contrário, a utilização das novas tecnologias deve ser difundida nas aulas de língua materna. As tecnologias devem ser consideradas como uma das estratégias para o desenvolvimento de competências do processo de escrita.

3 Essa discussão é fruto do projeto de pesquisa "Aprendizagem da língua escrita: interfaces com as TIC", coordenado pela Profa. Dra. Lucilene Lisboa de Liz, desenvolvido com apoio da Universidade do Estado de Santa Catarina. Para a aplicação dos questionários, contou-se com a preciosa colaboração das bolsistas de pesquisa, Alessandra Simões Trindade e Susana de Oliveira Vicente Martins, graduandas do Curso de Pedagogia a Distância, CEAD/UDESC, as quais agradecemos neste momento. 
Considera-se que ignorar a influência exercida pelas tecnologias de informação e comunicação (doravante TIC) no processo de aprendizagem da língua escrita é produzir uma escola que não cumpre com a sua função enquanto construtora do conhecimento. Uma escola que desconsidere as TIC torna-se, portanto, artificial, desconexa da sociedade da qual somos parte integrante, e privada de ferramentas com alto potencial de construção do saber.

$\mathrm{O}$ ensino de língua materna ${ }^{4}$ aliado às tecnologias aponta para a necessidade de que o professor possua conhecimentos sólidos sobre os processos envolvidos no uso da língua. Primeiramente, é preciso estar claro que há duas modalidades de língua distintas em jogo: a oral e a escrita. A apropriação da língua oral não ocorre da mesma forma que a apropriação da língua escrita. Também é importante ter uma concepção de língua que dê subsídios para as suas ações enquanto docente. A concepção de ensino está atrelada à concepção de linguagem. É uma atitude muito simplista reduzir as línguas humanas a um mero sistema de comunicação. Se assim o fosse, não haveria como distingui-las da linguagem de outros animais, por exemplo. As línguas naturais são flexíveis, versáteis, o que permite a criatividade humana.

O advento das TIC só favorece o desenvolvimento da produção escrita pela criança, que pode - com a instrução do professor - usar o computador para trabalhar diferentes habilidades de leitura e escrita. É imprescindível que os novos professores tenham familiaridade com as TIC a ponto de incorporá-las em suas aulas, tornando as mesmas mais atraentes e próximas da realidade de seus alunos.

A partir disso, pretende-se, neste artigo, realizar discussões que mostrem: (i) os pontos de vista de professores, que são alunos em formação por meio da modalidade $\mathrm{EaD}$, sobre a sua percepção diante da influência exercida pelas TIC durante o seu processo de escolarização, no que tange ao ensino-aprendizagem da escrita; (ii) a possibilidade de verificar se a forma como passaram por esse processo de aprendizagem da escrita apresenta algum reflexo em sua prática docente, ou seja, se a forma como aprenderam a escrita se repete na sua prática, mesmo passando por uma formação mediada pelo uso das TIC, no caso da modalidade EaD; (iii) a investigação da percepção desse aluno docente sobre a possível influência advinda do uso das TIC na produção escrita de seus alunos, com intuito de verificar se a formação no curso de graduação está superando a experiência em detrimento de uma formação mais ampla e sólida sobre os processos linguísticos envolvidos na aprendizagem da escrita; e (iv) a concepção de língua(gem) desse aluno/professor, com o objetivo também de vislumbrar

4 Neste estudo, emprega-se o termo língua materna com referência à língua portuguesa/ao português brasileiro. 
se os conteúdos ministrados nas disciplinas de ensino de língua/linguagem na graduação EaD superam a experiência do seu processo de escolarização. Para tanto, procedeu-se à aplicação de questionários, ainda em fase de pré-testagem, aos alunos da $\mathrm{EaD}$ que atuam na docência nas séries iniciais, mais especificamente no que diz respeito ao ensino de língua materna.

Este estudo está organizado da seguinte forma: primeiramente são apresentados os pontos teóricos que norteiam a discussão, os quais estão diretamente relacionados com o processo de ensino/aprendizagem da língua materna; esta seção, ainda, mostra como as TIC vêm sendo tratadas durante esse processo. Na próxima seção é apresentada a metodologia que subjaz à pesquisa. Em seguida, tem-se a análise e discussão dos dados. Por último, as considerações finais.

\section{Enfoques teóricos norteadores}

\section{O processo de ensino/aprendizagem da língua materna}

No que se refere à apropriação da língua oral, este estudo parte do pressuposto de que o ser humano é dotado de um órgão mental biológico que o capacita para adquirir qualquer língua natural. Essa aquisição ocorre de forma natural, isto é, sem intervenção do adulto e de modo inconsciente. Assim, quando a criança chega à escola já é um falante eficiente de sua língua materna, com domínio de sua estrutura e funcionamento. Já no que diz respeito à apropriação da língua escrita, essa ocorre de forma distinta, uma vez que necessita de mediação, de intervenção do professor/adulto.

A concepção de língua fundamentada na hipótese inatista aponta para um deslocamento da esfera do social para a esfera do psicológico e do biológico. De acordo com Chomsky $(1957,1965)$, pelo fato de mobilizar uma capacidade inata que é a mesma para todos os indivíduos da espécie humana, as línguas são muito parecidas entre si e isso tem importantes reflexos para o processo da aquisição da fala.

Cabe destacar que a capacidade de falar uma língua é diferente de outras habilidades cognitivas: tocar um instrumento musical ou resolver uma equação matemática requerem instrução específica, treino, e o resultado final varia muito de um indivíduo para outro. Já no que tange a habilidade de adquirir uma língua, verifica-se que se assemelha muito a outros processos biológicos, que são inatos no ser humano, como a capacidade de vir a andar, por exemplo (cf. COSTA; SANTOS, 2003). 
A exposição ao meio faz com que a criança tenha acesso ao input necessário para acionar o dispositivo da linguagem. A aquisição não é instantânea, a criança passa por estágios que ocorrem de acordo com o seu desenvolvimento maturacional. É preciso diferenciar o que é inato ao indivíduo do que é aprendido pelo indivíduo. Nesse sentido, Chomsky (1986) observa uma diferença relevante entre língua interna (língua-I) e língua externa (língua-E), sendo que o objeto de estudo da gramática é a língua-I. De acordo com Figueiredo Silva (2010), a língua-I é internalizada pelo falante e está por trás da sua produção linguística, enquanto a língua-E é uma manifestação social. O input a que a criança é exposta faz parte da língua-E e o que a criança desenvolve dentro de si é a língua-I.

A inserção da criança no mundo da escrita, no sentido de Kato (2005), de torná-la um indivíduo funcionalmente letrado, é uma função da escola. Tal afirmação não deveria ser apenas um pressuposto de estudiosos como o da referida autora, mas um pressuposto real de toda escola, de todo professor dos anos iniciais. No entanto, se fizermos um retrospecto para observar de que forma a escola vem trabalhando para formar um sujeito letrado, encontraremos uma série de equívocos, a começar pelos materiais didáticos que deveriam apoiar o professor nesta tarefa.

Esta breve incursão inicia-se pelos primeiros materiais didáticos, as cartilhas mais especificamente. Esses materiais apresentavam uma preocupação primordial com a leitura, realizada em forma de "decifração e identificação de palavras". Desse modo, lembra Cagliari (2002), as crianças tinham de dar conta de fazer a associação entre som e letra, de acordo com a ortografia vigente.

Na verdade, em português, a correspondência entre as letras e os sons é bastante complexa, o que cria para o professor muitas dificuldades previsíveis. Por isso, um professor de ensino de língua materna deve ter conhecimento técnico específico sobre a questão linguística que subjaz à alfabetização (cf. LEMLE, 1985). Dessa forma, terá condição de escolher a melhor forma de conduzir o processo de ensino.

Num segundo momento, a partir da década de 1950, partindo de uma preocupação em alfabetizar crianças carentes, que deveriam dominar a norma padrão, há uma mudança de foco para a escrita. Dentro dessa perspectiva, a alfabetização passou a ser caracterizada prioritariamente pelo ensino da escrita, ou como define Cagliari (2002, p. 26), pela utilização do "[...] método do ba-be-bi-bo-bu" / SILABAÇÃO" e relegou-se a um segundo plano o ensino da leitura.

E o panorama da alfabetização hoje? Pode-se afirmar que embora tenham ocorrido algumas interferências no processo de alfabetização, observa-se, na prática, ainda o respaldo nas cartilhas, mesmo que essas hoje recebam uma outra denominação. Por outro lado, há esforços por parte de alguns professores em remover a tralha gramatical e trabalhar o que realmente é relevante na alfabetização: a aprendizagem da escrita e da leitura como forma de se descobrir 
o mundo e a escrita por intermédio da linguagem. Com tantas mudanças nas legislações relacionadas à alfabetização, ressalta Cagliari (2002), verifica-se uma enorme confusão entre os professores que não sabem de que modo proceder nas turmas de séries iniciais: trabalha-se a leitura e a escrita e abandona-se a norma gramatical ou enfatiza-se a norma no trabalho da leitura e da escrita?

Cagliari (2002) chama atenção para o fato de que, diante desse quadro, os professores nem sequer sabem avaliar se os métodos ora oferecidos para o trabalho na alfabetização são bons ou ruins. A conclusão que se chega é a de que esse professor está mal preparado, visto que não se encontra capaz nem de julgar se o método que lhe foi exposto dá conta de alfabetizar seus alunos.

Portanto, parece que a resposta é óbvia: esse professor necessita de conhecimentos consistentes em linguística. Não menos óbvio é o fato de que para o professor obter tais conhecimentos, é fundamental uma mudança em toda a estrutura educacional, ou seja, as disciplinas destinadas ao ensino da língua deveriam conter maior carga horária e apresentar mais profundidade nos seus conteúdos para que o professor tivesse acesso a esse conhecimento técnico (próprio da área). O professor necessita de instrumentos que o capacitem, por exemplo, para um trabalho de correção dos "erros" de norma, presentes nos textos dos alunos; os tais erros em grande parte das vezes dizem respeito a um fenômeno de variação linguística. Dito de outro modo, em grande parte dos casos, o professor não está diante de erros, mas de escolhas de registro (linguístico), de variantes linguísticas diferentes da norma padrão privilegiada pela escola.

\section{As TIC e o ensino/aprendizagem de língua materna}

Segundo Miranda (2007), o termo Tecnologia da Informação e Comunicação (TIC) diz respeito ao entrelaçamento da tecnologia computacional com a tecnologia das telecomunicações, tendo sido a Internet (World Wide Web - www) a principal responsável pelo crescimento e potencialização da utilização das TIC. As tecnologias aparecem em diversos ramos de atividade, como nas indústrias, no comércio e no setor de investimentos. Quando as TIC são empregadas para melhorar a aprendizagem dos alunos ou desenvolver ambientes de aprendizagem, pode-se considerá-las como um subdomínio da tecnologia educativa.

De acordo com Kenski (2003), quando o ensino é mediado pelas tecnologias digitais, a relação professor-aluno assume um novo caráter, uma vez que os ambientes digitais oferecem novos espaços e tempos de interação entre aquele que ensina e aquele que aprende. Com a abertura de diferentes espaços, as relações entre os sujeitos da escola se potencializa, pois o ensino, a aprendizagem e a gestão escolar podem se desenvolver num processo colaborativo (cf. ROSA; CECÍLIO, 2010). 
Com o advento das TIC observa-se uma mudança significativa no dia a dia, no comportamento dos indivíduos, e nos modos de aprendizagem. A inserção do indivíduo no mundo digital confere-lhe novas experiências e novas formas de usos sociais da leitura e da escrita. Nesse sentido, não é difícil perceber que essas tecnologias podem intervir no processo de aprendizagem da escrita, por meio de um processo de ensino/aprendizagem mais dinâmico. Assim, deve-se verificar qual é o tipo de influência que as TIC têm exercido sobre a escrita das crianças em fase de aprendizagem da língua portuguesa, visto que uma das formas de a criança estabelecer contato com as letras se dá a partir das TIC.

Dada essa presença tão incisiva, os professores estão diante de um novo desafio: lidar com a questão da aprendizagem da língua escrita diante da influência das TIC. Em grande parte dos casos, esse professor não detém o conhecimento linguístico necessário para tratar da questão de aprendizagem da língua escrita nem tampouco está familiarizado com as TIC e com a forma como elas podem intervir nesse processo. É nesse âmbito que o presente trabalho pretende se colocar: investigar se as TIC estão influenciando na aprendizagem da escrita e ainda de que modo atua essa influência.

A missão do professor de ensino de língua ganhou mais um desafio com a chegada das TIC, pois além dos considerados "problemas normais" do período de aprendizagem da língua escrita, esse professor encontra interferências distintas das que ele costumava encontrar nos "erros" dos seus alunos. Na maioria das vezes, esse professor desconhece inclusive a origem dos tais "erros" de escrita. Então, mais do que entender o que se passa no processo de aprendizagem da língua escrita, o professor necessita saber qual é a ascendência desses "erros". Acrescente-se a isso o fato de que a criança hoje parece estabelecer o seu primeiro contato não mais com os livros, mas tendo como suporte as TIC.

O processo de aprendizagem e o posterior domínio da língua escrita causam uma transformação na vida do indivíduo, já que o que era apenas um "desenho" passa a fazer sentido. Mas essa aprendizagem envolve um processo bastante complexo e exige muita paciência tanto do professor dos anos iniciais quanto do aluno, visto que para sua aquisição, a criança tem de aprender as diferenças do sistema grafêmico, fonológico, morfológico e semântico até chegar às diferenças do domínio sintático. Essas etapas do processo de aquisição da escrita não parecem ser diferentes quando a criança tem diante de si as TIC, mas se percebe uma ampliação das práticas discursivas. E por que diferentes práticas? Ora, ao ter seu computador conectado à internet, por exemplo, a criança-internauta passa a ocupar e a atuar em diferentes espaços diante da leitura e textos diversos. Ainda, observa-se que o contato frequente com as novas tecnologias faz surgir uma nova forma de linguagem, uma nova manifestação 
de língua escrita, quer seja com o aparecimento de ícones ou de abreviações que surgem com o objetivo de acompanhar o dinamismo/rapidez do mundo digital.

As TIC devem ser utilizadas a favor de um ensino mais eficiente e eficaz, para que tanto o professor quanto o aluno tenham sucesso durante o processo de aprendizagem. Rodrigues afirma que:

Se as novas tecnologias trazem novos desafios às escola de hoje, são dela indissociáveis, consequência de uma sociedade competitiva e exigente condicionada pelo digital e pela necessidade de actualização constante. Hoje mais do que nunca, as instituições de ensino devem reflectir sobre a utilidade da introdução das novas tecnologias de informação e comunicação (TIC) nas actividades e currículos escolares (RODRIGUES, 2009, p. 6).

A realidade mostra que algumas escolas têm dificuldades de realizar uma reorganização curricular para promover a implementação de práticas pedagógicas inovadoras. Muitas vezes os professores também resistem ao uso das TIC pela comodidade de permanecer no método de ensino tradicional.

A escola não pode ficar alheia ao avanço tecnológico que vem ocorrendo no mundo. Cabe a ela saber que tipo de sujeito quer ajudar a formar. Por isso, é importante que sejam criadas condições adequadas para o professor elaborar e operacionalizar projetos educacionais que explorem as tecnologias disponíveis na sociedade atual. Também é papel da escola possibilitar aos professores uma formação continuada que os permita dominar o conteúdo que deve ser trabalhado com os alunos. Sabe-se que as TIC, ainda que diretamente relacionadas ao contexto escolar, não solucionam os problemas de ensino/aprendizagem. O uso das TIC será bem-sucedido quando o professor tiver domínio de conteúdo e estratégias que possibilitem a aprendizagem em cada situação de ensino.

No caso do ensino da língua materna, por mais que o professor se esforce em trabalhar com o uso das TIC, se não possuir um conhecimento linguístico acurado, terá maiores chances de fracassar na sua prática pedagógica. Por isso, é preciso que o professor dos anos iniciais tenha uma formação que lhe garanta o desenvolvimento/aperfeiçoamento de habilidades que o tornem um profissional crítico, reflexivo e criativo. Dessa forma, o professor estará preparado para utilizar as TIC como uma ferramenta a favor da educação.

O professor dos anos iniciais que vai trabalhar o ensino de língua materna pode utilizar as tecnologias para desenvolver em seus alunos competências relacionadas à língua portuguesa. Para tanto, os professores podem utilizar 
materiais on-line para o planejamento de suas aulas, integrar hipertextos nas atividades que vai propor, selecionar os sítios adequados aos alunos, de acordo com o objeto de estudo, acompanhar seus alunos nos momentos de pesquisa, construindo roteiros que os orientem durante a busca. Enfim, o professor deve usar os recursos tecnológicos de forma que leve "o aluno a compartilhar os saberes individuais, a formular e solucionar questões e a buscar informações contextualizadas às dinâmicas sociais de aprendizagem." (QUEVEDO; CRESCITELLI, 2005, p. 47).

\section{Metodologia}

Essa pesquisa é de natureza qualitativa, embora em alguns momentos faça-se uso de dados estatísticos, e contou como instrumento de coleta de dados a aplicação de questionários. Os sujeitos de pesquisa são alunos de quatro polos do curso de Pedagogia da UDESC, na modalidade EaD, que já atuavam como professores na educação infantil e nas séries iniciais.

Para a coleta de dados da presente pesquisa, foi realizada a aplicação de um questionário. Cientes da "arte imperfeita" desse instrumento de coleta, nos termos de Aaker, Kumar e Day (2001), já que não há método preciso que assegure que os objetivos de medição sejam atingidos com a acurácia que se deseja, procuramos seguir algumas orientações do referido autor em relação aos procedimentos de elaboração do questionário, a saber, ter bom senso e evitar questões ambíguas, além é claro do emprego de uma linguagem adequada aos sujeitos de pesquisa ${ }^{5}$.

O questionário aplicado continha 10 perguntas elaboradas em duas categorias: fechada e semiaberta. No que se refere à categoria perguntas fechadas, em que as respostas possíveis são estabelecidas de antemão, as questões foram elaboradas do seguinte modo: (a) perguntas com previsão de respostas "sim" ou "não", denominadas como dicotômicas; (b) perguntas que admitem um número expressivo de respostas possíveis, também conhecidas como múltipla escolha. Já no que se refere à categoria fechada de perguntas, optou-se pela categoria semiaberta, seguida de questões como: de que modo? Por quê?

5 Após a aplicação do pré-teste, questionários que foram analisados para essa discussão, percebeu-se a necessidade de adequar ainda mais o uso da linguagem para os sujeitos de pesquisa, o que só vem a validar a necessidade de ajustes de natureza linguística e de realização de pré-testes. 
Para esta discussão, o enfoque será sobre a análise de quatro questões aplicadas nesse instrumento de coleta de dados:

i. As tecnologias influenciavam na forma como você aprendeu a escrita e a leitura?

ii. A forma como você passou pelo processo de aprendizagem da escrita exerce alguma influência na sua prática pedagógica?

iii. Você percebe alguma influência do uso das tecnologias na escrita dos seus alunos (TIC)?

iv. O que é língua para você?

O objetivo da presente discussão, no que tange ao ensino-aprendizagem de língua materna, é investigar se o modo como esse professor passou pelo processo de aprendizagem da escrita influencia na forma como hoje exerce a sua prática docente, vislumbrando a sua percepção sobre a influência das TIC na produção escrita dos seus alunos. E, subjacente a isso, observar se a experiência supera a formação, dito de outro modo, se a experiência enquanto aluno, e a partir dela a apropriação de conhecimentos, é mais significativa e aplicada a sua docência do que os conhecimentos adquiridos via formação, que hoje recebem no curso de Pedagogia da UDESC na modalidade EaD.

\section{Análise e discussão dos dados}

No atual contexto tecnológico e sociocultural, as crianças têm acesso a gêneros discursivos diversos, disponíveis em suportes de dispositivos eletrônicos que utilizam diariamente. Diante disso, torna-se imprescindível um olhar atento sobre o comportamento docente e sua percepção diante da influência dessas TIC na produção escrita da criança. Se por um lado, ao observarmos, sob o enfoque inatista, o processo de aquisição de linguagem oral, é perceptível que o input gerado pelo ambiente linguístico que cerca a criança está repleto de novos termos advindos do uso das TIC e passam a fazer parte do seu léxico mental; por outro, essa influência deve também ser visível e compreendida, por parte de professores, no momento de apropriação da língua escrita pela criança. Mas o vislumbre e a compreensão desse fato devem ser acompanhados de um tratamento adequado no momento em que o professor está exercendo sua docência, tanto no que se refere ao uso de recursos tecnológicos como recursos didáticos, como no que diz respeito ao tratamento dos dados linguísticos produzidos pela criança em sua escrita. Para tanto, frisou-se até aqui uma concepção de língua clara e atual que considera que os processos linguísticos imbricados no momento da produção escrita são cruciais. 
Crystal (2001 apud MARCUSCHI, 2004, p. 18-19) destaca três aspectos da linguagem utilizada nos gêneros discursivos que circulam em sites da Internet:

a) do ponto de vista dos usos da linguagem, temos uma pontuação minimalista, uma ortografia um tanto bizarra, abundância de siglas, abreviaturas nada convencionais, estruturas frasais pouco ortodoxas e uma escrita semi-alfabética;

b) do ponto de vista da natureza enunciativa dessa linguagem, integram-se mais semioses do que usualmente, tendo em vista a natureza do meio com participação mais intensa e menos pessoal, surgindo a hiperpessoalidade;

c) do ponto de vista dos gêneros realizados, a Internet transmuta de maneira bastante complexa gêneros existentes, desenvolve alguns realmente novos e mescla vários outros.

$\mathrm{O}$ fato inconteste é que a Internet e todos os gêneros a ela ligados são eventos textuais fundamentalmente baseados na escrita (MARCUSCHI, 2004, p. 19).

Outras características da linguagem digital são elencadas por Santos:

A linguagem digital também se caracteriza pela redução das palavras (cortes realizados em alguns vocábulos, tendo como princípio norteador o som que eles evocam, a exemplo de q, vc, blz, kra, kd para indicar, respectivamente, que, você, beleza, cara, cadê). Além disso, distingue-se pela marcação de sílabas tônicas através do uso da letra $\mathbf{h}$ no final do vocábulo (a exemplo de soh para indicar só), por modificações na representação convencional dos sons nasais (como, por exemplo, o uso de naum e baum para representar os vocábulos não e bom) e pelo uso de gírias (SANTOS, 2010, p. 8).

Admitindo-se a posição de Marcuschi (2004) de que através da Internet, uma tecnologia na qual circulam muitos textos escritos, ocorre o contato cada vez mais comum de crianças com as TIC, tende-se a acreditar que a linguagem típica de gêneros que circulam na Internet se fará presente na produção escrita ${ }^{6}$ da criança durante o seu processo de apropriação. Nesse sentido, o professor

6 Essa hipótese está sendo verificada paralelamente por meio de investigação de produção textual de crianças em fase de aprendizagem da língua escrita, mais propriamente nas séries iniciais do Ensino Fundamental. 
deve fugir do lugar comum em considerar que a escrita peculiar a textos veiculados nesse meio tecnológico irá contaminar ou mesmo prejudicar o desenvolvimento da aprendizagem da língua escrita pela criança. Ora, desde o processo de aquisição de língua oral, sabe-se da destreza com que a criança manipula as regras gramaticais de sua língua materna; no que concerne ao processo de aprendizagem da escrita, se a criança for acompanhada por um processo de mediação do professor de maneira adequada, a competência linguística que revela em relação à língua oral, de modo distinto e também de forma eficiente, poderá desenvolver uma competência comunicativa e textual, no tangente à aprendizagem da língua escrita.

Dentro desta perspectiva é que se pretende problematizar os seguintes pontos: a percepção do professor dos anos iniciais, aluno do curso de Pedagogia da UDESC da EaD, sobre a influência das TIC na produção escrita da criança; se a forma como foram alfabetizados e/ou aprenderam a escrita exerce alguma influência sobre a sua prática como docentes hoje; verificar a concepção de língua(gem) desse professor.

Para levar a termo a tarefa de realizar essa problematização de forma séria e científica, parte-se da análise de questionários aplicados conforme descrito na seção metodológica do presente artigo, com enfoque em quatro pontos, repetidos aqui.

i. As tecnologias influenciavam na forma como você aprendeu a escrita e a leitura?

ii. A forma como você passou pelo processo de aprendizagem da escrita exerce alguma influência na sua prática pedagógica?

iii. Você percebe alguma influência do uso das tecnologias na escrita dos seus alunos (TIC)?

iv. O que é língua para você?

Antes, porém, de proceder à descrição e à análise dos dados, deve-se fazer uma ressalva: os sujeitos de pesquisa, no período de aplicação do questionário, já haviam cursado duas disciplinas de ensino de língua(gem), no curso de Pedagogia EaD da UDESC, as quais enfatizavam a necessidade de se ter concepções claras de língua(gem) norteando a sua prática docente. Diante disso, esperava-se que essas disciplinas já tivessem mobilizado uma massa crítica em relação ao ensino de língua, principalmente, no que concerne à adoção de uma (ou mais) concepção(ões) de língua(gem).

Quando perguntados se o uso dos recursos tecnológicos da época auxiliavam/influenciavam no processo de aprendizagem da língua(gem) escrita, questão (i), a maior parte das respostas foi afirmativa, de um total de 34 questionários, 25 sujeitos responderam que $\operatorname{sim}$ e apenas 9 sujeitos responderam que $n a \tilde{o}$. 
Ao analisar as respostas negativas apresentadas a essa questão, percebe-se que estão associadas aos seguintes fatos: não haver recursos tecnológicos à disposição para servir como recurso didático ao processo de ensino-aprendizagem (em sete das respostas negativas); ou ao fato de os recursos tecnológicos à disposição não serem utilizados como recurso didático (em duas das respostas negativas). De acordo com os informantes, as tecnologias acessíveis durante o seu processo de aprendizagem da língua escrita consistiam em videocassete, videogame e televisão.

Com o avanço na produção de tecnologias, hoje há diferentes recursos tecnológicos que podem servir de apoio pedagógico com o intuito de auxiliar pedagogicamente o professor no ensino de graduação. Na sala de aula, o docente pode fazer uso do quadro e giz, além de mídias como Internet e recursos como o datashow. No entanto, se não houver clareza dos propósitos de ensino-aprendizagem, nenhum recurso tecnológico poderá surtir um efeito positivo. No que concerne ao ensino de língua na $\mathrm{EaD}$, foco da nossa discussão, parece-nos cada vez mais claro que se o professor não conhecer o processo pelo qual o sujeito aprendiz passa de um processo de apropriação da língua oral para apropriação da língua escrita e, a partir disso, não perceber a influência do primeiro processo sobre o segundo, nenhuma tecnologia como recurso didático poderá culminar em sucesso no desenvolvimento das habilidades linguísticas almejadas. Isso fica evidente quando atentamos para as questões (i) e (ii).

Com relação à pergunta (ii), sobre se a forma como passou pelo processo de aprendizagem da escrita exerce alguma influência na sua prática docente ao ensinar a escrita aos seus alunos, obtiveram-se 20 respostas não e 14 respostas sim, dos 34 questionários analisados.

Ao analisar o conjunto de perguntas e respostas, é possível perceber que as respostas não refletem a realidade, ao menos não se considerarmos a concepção de língua do professor que já passou por duas disciplinas da área da linguística que problematizam e apresentam concepções de língua claras e consistentes com a prática pedagógica. Para tanto, considere as respostas obtidas a partir do instrumento de coleta de dados da questão iv, referente à concepção de língua(gem) dos sujeitos de pesquisa:

QUADRO 1 - CONCEPÇÃO DE LÍNGUA(GEM) DOS PARTICIPANTES

\begin{tabular}{|l|c|}
\hline Respostas & Ocorrência \\
\hline Língua(gem) como instrumento de comunicação & $\mathbf{2 6}$ \\
\hline Língua(gem) como forma de interação & $\mathbf{2}$ \\
\hline Língua(gem) como expressão de pensamento & $\mathbf{3}$ \\
\hline Língua(gem) apresentada não é clara & $\mathbf{3}$ \\
\hline
\end{tabular}

FONTE: Dados analisados nos questionários. 
Fica evidente, na maioria das respostas, a concepção de língua herdada do período em que passaram pelo processo de aprendizagem da língua escrita, a saber, a concepção de língua como instrumento de comunicação. Concepção essa que foi superada dentro dos estudos da linguagem e, em razão disso, não se apresenta como enfoque dentro das disciplinas da área de linguística no curso de Pedagogia na modalidade EaD, foco dessa investigação.

E de que trata essa concepção de linguagem e por que a adoção dessa concepção é tão problemática?

Dentro dessa concepção, a linguagem, segundo Liz (2012, p. 24), tem como função única a transmissão de informações. Nessa perspectiva, concebe-se a língua como um código, formado a partir dos níveis fonológico, morfológico e sintático, o qual deve ser "aprendido" pelos falantes para que a comunicação se efetive. Trata-se de uma concepção pautada num esquema de comunicação vencido, mas que está presente em grande parte dos livros didáticos de ensino de língua portuguesa e está associada ao ensino gramatical tradicional.

No entanto, mesmo que os professores tenham respondido em sua maioria que o modo como aprenderam a escrita na escola não exerce influência na sua prática docente, fica evidente a partir das respostas à pergunta (iii) que o modo como passaram pelo processo de aprendizagem da língua escrita de algum modo se reflete na sua prática ao adotarem uma concepção de língua corrente no momento em que passaram pelo processo de aprendizagem da escrita, a saber, a concepção de linguagem como instrumento de comunicação. Basta perceber que dentre os 34 dados coletados, 27 apontam para uma concepção de língua como instrumento de comunicação. Sendo assim, as respostas às questões (ii) e (iv) revelam, de certo modo, que as experiências advindas do ensino de língua se refletem ainda hoje na forma como atuam, já que mesmo diante de novas e atuais concepções de língua, estudadas durante sua formação no curso de graduação $\mathrm{EaD}$, perpetua-se a mesma concepção.

$\mathrm{Na}$ análise das respostas dadas à questão (iii), quando questionados sobre a percepção da influência do uso das TIC na aprendizagem da escrita da criança, verifica-se que todos os participantes reconhecem a influência das TIC, uma vez que todos responderam sim.

No entanto, quando se parte para a análise das perguntas abertas sobre de que modo essa influência se manifesta concretamente na produção escrita da criança, é evidente a confusão entre o processo de aprendizagem mais geral e as características mais específicas na produção escrita da criança e mesmo a falta de visão desses traços linguísticos.

As respostas direcionam-se para a compreensão das TIC como facilitador desse processo mais geral de aprendizagem da língua escrita; em apenas um caso as TIC apareceram como empecilho. Isso pode dever-se em parte à necessidade 
de ajustes no instrumento ou à não compreensão dos fenômenos linguísticos envolvidos no processo de apropriação da língua escrita e de como tratá-los ${ }^{7}$.

Dentre os dados analisados, somente em um deles o professor mostra percepção sobre o uso das TIC e sua relação com a aprendizagem da escrita, reconhecendo que o aluno utiliza a forma linguística própria de gêneros discursivos que circulam em suportes tecnológicos e também em outros gêneros que não são próprios dessa esfera de circulação. Observe a resposta abaixo ${ }^{8}$ :

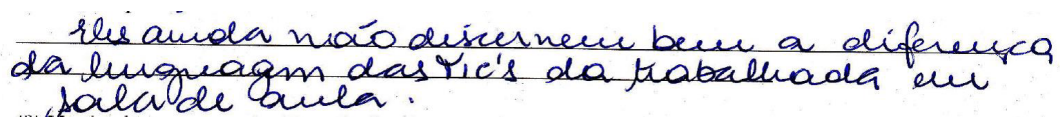

Adicionalmente, observa-se nos dados a forte presença de lugares comuns nas respostas desses sujeitos da pesquisa, como se verifica na resposta que segue ${ }^{9}$ :

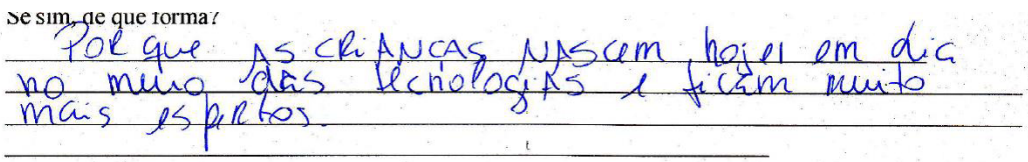

Dados como esse podem ser analisados à luz do reflexo da pouca apropriação dos conteúdos estudados no curso ou mesmo do fato de a experiência estar superando a formação que esses alunos/professores estão recebendo.

Nessa perspectiva, é importante frisar que esses professores participantes do estudo, alunos do curso de Pedagogia da UDESC, na modalidade EaD, deverão frequentar até o fim de sua formação sete (7) disciplinas na área da linguística, voltadas para o ensino de língua e dos aspectos linguísticos imbricados na aquisição da língua oral e na aprendizagem da escrita. Então, se por um lado, preocupa essa pouca apropriação de conhecimentos advindos dos conteúdos estudados, por outro, reacende a expectativa de que as discussões no andamento desses estudos se reflitam em dados futuros, no sentido de evidenciar maior apropriação dos processos linguísticos envolvidos na aquisição de língua oral e seus reflexos na aprendizagem da escrita.

7 Diante dos dados obtidos a partir desse questionário, buscar-se-á refinar o instrumento para uma nova aplicação. de aula.'

8 "Eles ainda não discernem bem a diferença da linguagem das TIC da trabalhada em sala

9 "Porque as crianças nascem hoje em dia no meio das tecnologias e ficam muito mais espertos." 


\section{Considerações finais}

A análise dos dados mostra que a grande maioria dos sujeitos de pesquisa reconhece a influência das TIC no processo de ensino/aprendizagem da língua materna. Contudo, os participantes ainda carecem de apropriação de conteúdo para melhor aproveitamento das tecnologias em sala de aula.

Se o professor não conhecer o processo pelo qual o sujeito aprendiz passa de um processo de apropriação da língua oral para apropriação da língua escrita e, a partir disso, não perceber a influência do primeiro processo sobre o segundo, nenhuma tecnologia como recurso didático poderá culminar em sucesso no desenvolvimento das habilidades linguísticas almejadas.

Quando questionados sobre o modo como foram alfabetizados e a concepção de língua(gem) que possuem, os sujeitos de pesquisa revelam, de certo modo, que as experiências advindas do ensino de língua se refletem ainda hoje na forma como atuam. Mesmo diante de concepções de língua mais atuais, estudadas durante a sua formação, os participantes carregam a concepção que subsidiou o seu processo de alfabetização.

No geral, observa-se que as TIC vêm sendo assimiladas de diferentes maneiras, com diferentes graus de utilização, pelos professores de ensino de língua materna dos anos iniciais. Esta realidade desperta para a necessidade de novas propostas de ensino. Mas cabe destacar que o uso das TIC só passa a ter sucesso quando o professor domina o conteúdo a ser trabalhado; quando tem clareza acerca da concepção de língua que rege o processo de ensino; quando reconhece a distinção entre a língua oral e a língua escrita; quando percebe que a produção escrita da criança é criativa, com aspectos gramaticais que merecem ser investigados, não apenas "corrigidos" como se fossem simples "erros de português" ou "desvios de norma padrão".

\section{REFERÊNCIAS}

AAKER, D. A.; KUMAR, V.; DAY, G. S. Pesquisa em marketing. São Paulo: Atlas, 2001. ALAVA, S. Ciberespaço e formações abertas: rumo a novas práticas educacionais. Porto Alegre: Artmed, 2002.

CAGLIARI, L. C. Alfabetização e Linguística. 10. ed. São Paulo: Scipione, 2002. 
CAGLIARI, L. C. Alfabetizando sem o bá-bé-bi-bó-bu. São Paulo: Scipione, 1999.

CAGLiARI, G; CAGLIARI, L. C. Diante das Letras. A Escrita e Alfabetização. São Paulo: FAPESP, 1999.

CHOMSKY, N. Syntact Structure. Haia, Mouton, 1957.

CHOMSKY, N. Aspects of the Theory of Syntax. Cambridge: MIT Press, 1965.

CHOMSKY, N. Knowledge of language: is nature, origin and use. New York: Praeger, 1986.

CHOMSKY, N. The Minimalism Program. Cambridge, MA: MIT Press, 1995.

COSTA, J.; SANTOS, A. L. A falar como os bebés: o desenvolvimento linguístico das crianças. Lisboa: Caminho, 2003.

FIGUEIREDO SILVA, M. C. Aquisição da Linguagem. Florianópolis: LLV/UFSC, 2010.

KATO, M. A. A concepção da escrita pela criança. Campinas/SP: Fontes, 1992.

KATO, M. No mundo da escrita: uma perspectiva psicolinguística. 7. ed. São Paulo: Ática, 2005.

KENSKI, V. M. Tecnologias e ensino presencial e a distância. Campinas: Papirus, 2003.

LEMLE, M. Guia teórico do alfabetizador. São Paulo: Ática, 1985.

LIZ, L. L. de. Do inatismo ao interacionismo: aquisição e a aprendizagem da língua escrita influenciada pelas TIC. In: FONSECA da SILVA, M. C. R. (Org.). Anais do IX Encontro do Grupo de Pesquisa Educação, Artes e Inclusão. Florianópolis: UDESC, 2013.

LIZ, L. L. de. Língua(gem), Gramática e Ensino. In: DAGA, A. C. et. al. Conteúdos e Metodologias do Ensino de Linguagem I. Florianópolis: DIOESC, 2012.

MARCUSHI, L. A. Gêneros virtuais emergentes no contexto da tecnologia digital. In: MARCUSCHI, L. A.; XAVIER, A. (Orgs.). Hipertexto e gêneros digitais: novas formas de construção do sentido. Rio de Janeiro: Lucerna, 2004.

MIRANDA, G. L. Limites e possibilidades das TIC na educação. Lisboa, 2007. Disponível em: <http://sisifo.fpce.ul.pt>. Acesso em: 13 mar. 2014.

MOORE, M.; KEARSLEY, G. Educação a Distância. São Paulo: Thomson Pioneira, 2007.

PALLOFF, R. M.; PRATT, K. Construindo comunidades de aprendizagem no ciberespaço. Porto Alegre: Artmed, 2002.

QUEVEDO, A. G.; CRESCITELLI, M. Recursos tecnológicos e o ensino de língua materna e estrangeira (a distância e semipresencial). São Paulo, 2005. Disponível em: $<$ http:// www.revistas.fflch.usp.br/linhadagua/article/view/145/151>. Acesso em: 10 out. 2013. 
RODRIGUES, R. Prefácio. In: SANTOS, L.; SIMÕES, D. (Orgs.). Ensino de Português e Novas Tecnologias. Coletânea de textos apresentados no I SIMELP. Rio de Janeiro: Dialogarts, 2009. 160 p.

ROSA, R.; CECÍLIO, S. Educação e o uso pedagógico das tecnologias: a produção do conhecimento em análise. Juiz de Fora, 2010. Disponível em: <http://www.ufjf. br/ revistaedufoco/files/2011/05/Artigo-0x-15.1-Rosemar.pdf >. Acesso em: 15 nov. 2013.

SANTOS, M. Por uma outra globalização: do pensamento único à consciência universal. 9. ed. Rio de Janeiro: Record, 2010.

Texto recebido em 22 de novembro de 2014. Texto aprovado em 10 de dezembro de 2014. 